\title{
Modelling population effects of juvenile offshore fish displacement towards adult habitat
}

van de Wolfshaar, K.E.; Tulp, I.; Wennhage, H.; Støttrup, Josianne

Published in:

Marine Ecology - Progress Series

Link to article, DOI:

$10.3354 /$ meps 11519

Publication date:

2015

Document Version

Publisher's PDF, also known as Version of record

Link back to DTU Orbit

Citation (APA):

van de Wolfshaar, K. E., Tulp, I., Wennhage, H., \& Støttrup, J. (2015). Modelling population effects of juvenile offshore fish displacement towards adult habitat. Marine Ecology - Progress Series, 540, 193-201.

https://doi.org/10.3354/meps11519

\section{General rights}

Copyright and moral rights for the publications made accessible in the public portal are retained by the authors and/or other copyright owners and it is a condition of accessing publications that users recognise and abide by the legal requirements associated with these rights.

- Users may download and print one copy of any publication from the public portal for the purpose of private study or research.

- You may not further distribute the material or use it for any profit-making activity or commercial gain

- You may freely distribute the URL identifying the publication in the public portal 


\title{
Modelling population effects of juvenile offshore fish displacement towards adult habitat
}

\author{
K. E. van de Wolfshaar ${ }^{1, *}$, I. Tulp ${ }^{1}$, H. Wennhage ${ }^{2}$, J. G. Støttrup ${ }^{3}$ \\ ${ }^{1}$ Wageningen IMARES, PO Box 68, 1970 AB, IJmuiden, The Netherlands \\ ${ }^{2}$ Institute of Marine Research, Department of Aquatic Resources, Swedish University of Agricultural Sciences, Turistgatan 5, \\ 45330 Lysekil, Sweden \\ ${ }^{3}$ Technical University of Denmark, National Institute of Aquatic Resources, Charlottenlund Castle, 2920 Charlottenlund, \\ Denmark
}

\begin{abstract}
Recent studies of fish distribution patterns highlight shifts in the spatial distributions of particular life-stages. Focus has thus far been on changes in habitat use and possible drivers for these changes. Yet, small-scale shifts in habitat use of certain life stages may have profound consequences on population dynamics through changes in resource use and competition. To explore this, a conceptual stage-structured model was developed with 3 stages and 2 resources and allowing a move of large juveniles from the shallow to the deep habitat. Large juveniles compete with small juveniles in shallow waters and with adults in deeper waters. Alternative stable states occur, with one state dominated by small juvenile biomass and the other dominated by adult biomass. The model results show for both states that while large juvenile biomass responds to a change in time spent in the deep habitat, the biomass of small juveniles and adults is barely affected. Between the 2 states there is a profoundly different population response to increased fishing mortality. In the adult biomass dominated state, adult biomass is hardly affected while juvenile biomass increases until population collapse, with increased fishing. In the small juvenile dominated state, adult and small juvenile biomass decrease, and large juvenile biomass increases. This state persists at much higher fishing mortality than the adult biomass dominated state. This study highlights that safeguarding nursery functions in a changing environment requires monitoring of juvenile life-stages in a range of habitats and a spatially adaptive management strategy.
\end{abstract}

KEY WORDS: Stage-structured model $\cdot$ Complex life cycle $\cdot$ Nursery grounds $\cdot$ Spatial distribution • Competition

Resale or republication not permitted without written consent of the publisher

\section{INTRODUCTION}

Coastal ecosystems are globally among the most productive marine systems, providing habitat in which to feed and grow for many fish species, a large part of which are commercially exploited (Seitz et al. 2014). Increasing anthropogenic pressures have given rise to growing concern for the resilience of these systems and sustainability of their resources (Harley et al. 2006, McClanahan et al. 2015). This concern has highlighted the need for appropriate integrated management (Hopkins et al. 2011). Coastal habitats are important nurseries for fish, where habitat size and quality strongly influence stock size of commercially important species through growth, survival and connectivity with spawning areas (Gibson 1994). The often complex life cycles require understanding across the entire life cycle in order to anticipate responses of fish populations to external pressures (Petitgas et al. 2013).

In recent decades, considerable changes in the distribution of fish have been reported, and these 
changes are increasingly considered as direct or indirect biological responses to the warming of the oceans (Edwards et al. 2002). Distributions of boreal and Lusitanian species move northward, with the Lusitanian species possibly replacing the boreal species in areas of spatial co-occurrence at temperate latitudes (Beare et al. 2004, Rijnsdorp et al. 2009, Petitgas et al. 2013). Besides large-scale shifts of boreal species such as plaice Pleuronectes plattessa and cod Gadus morhua towards northern regions (Rindorf \& Lewy 2006), small-scale shifts towards deeper waters where temperatures are lower have been observed in several fish species in European waters and elsewhere (Dulvy et al. 2008).

The change in habitat use from coastal habitat to deeper habitat by a certain life stage implies life stage-dependent shifts in feeding habitats. The consequence of such a shift is that the competitive interactions change when life stages begin or cease to share a habitat. Van Keeken et al. (2007) showed that as a result of the movement of juvenile plaice towards deeper waters, the mean crowding decreased for smaller-sized plaice in the shallows, while it increased for larger-sized plaice in deeper waters. Such a shift in the potential for intra-specific competition between life stages may have consequences at the population level. Additionally, a shift of large juveniles towards deeper areas implies an increase in vulnerability to fisheries as fisheries generally operate more intensely in the deeper areas.

Plaice is the most well studied species within the context of juvenile habitat shifts owing to its commercial importance, but the movement towards deeper areas has been observed for more species such as dab Limanda limanda (van Hal et al. in press), megrim Lepidorhombus whiffiagonis, grey gurnard Eutrigla gurnardus, cod Gadus morhua, whiting Merlangius merlangus, long rough dab Hippoglossoides platessoides, angler Lophius piscatorius, lemon sole Microstomus kitt, poor cod Trisopterus minutus and cuckoo ray Leucoraja naevus (Dulvy et al. 2008). Until now, the phenomenon of large juvenile plaice shifting habitat has been studied at the level of individual fish (e.g. Rijnsdorp et al. 2009), from a bycatch perspective (van Keeken et al. 2007) and in relation to possible physiological mechanisms (e.g. Teal et al. 2012). More general studies on the use of shallow habitat by fish have mostly focussed on predicting presence-absence and/or abundance patterns based on habitat suitability (e.g. Vasconcelos et al. 2013). However, to date, the population dynamic consequences of habitat shifts for juvenile fish towards deeper areas have not been examined. Yet changes in competitive interactions may have profound effects on the biomass distribution along life stages and may give rise to alternative stable states (e.g. Schröder et al. 2005, De Roos et al. 2008). Here, the effects of a habitat shift of juveniles on the population dynamics are explored using a generalized mathematical description of such a system inspired by the observations in the North Sea (Dulvy et al. 2008, Teal et al. 2012, van Hal et al. in press).

To study the population dynamic effects of larger juveniles shifting habitat and thus shifting the scope for competition between stages within a population, a biomass-based stage-structured model (De Roos et al. 2008, van de Wolfshaar et al. 2011, 2012) was developed. This type of model combines resourcedependent growth and maturation with stagestructure and allows for a mechanistic underpinning of emergent patterns in population dynamics. The model allows for a conceptual exploration of possible population dynamical responses to a habitat shift of large juveniles and changes in intra-specific competition, which may occur for a range of species (Dulvy et al. 2008, van Hal et al. in press). The model results describe the equilibrium population dynamics of a model fish species with 3 life stages foraging in 2 habitats each with 1 resource (Fig. 1). The model results are based on a generalized parameterization for ectothermic species (van de Wolfshaar et al. 2011).

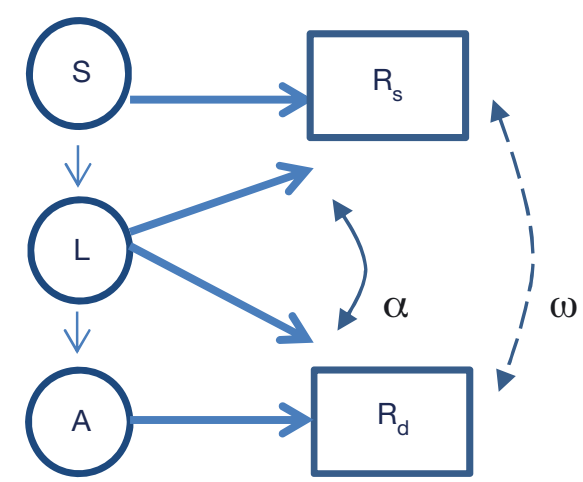

Fig. 1. Model representation of the plaice population. Small juveniles $(\mathrm{S})$ have their resource in the shallow area $\left(R_{\mathrm{S}}\right)$, while adults $(A)$ have their resource in the deep areas $\left(R_{d}\right)$. Large juveniles (L) may change from feeding solely on the resource in the shallows $\left(R_{s}\right)$ to feeding solely on the resource in the deep areas $\left(\mathrm{R}_{\mathrm{d}}\right)$ by changing the value of $\alpha$. $\omega$ scales the carrying capacity of both resources such that their sum always equals $K_{\mathrm{m}}$. Thin arrows between stages indicate growth 


\section{MODEL AND PARAMETER ESTIMATES}

\section{Consumer-resource model}

To study the effect of changing habitat during ontogeny, a biomass-based stage-structured population model was used (De Roos et al. 2008) and parameterized for ectotherms. Such models are conceptual in the sense that only a limited set of assumptions is considered for exploration; emerging mechanisms may be incorporated in more complex simulation models.

In this type of model, growth and reproduction rates are resource dependent. The stages are based on size, and based on the size limits chosen, a certain amount of growth needs to be realized for each stage. To mature to the next stage (or to reproduce), a certain amount of energy is needed, and with differences in allometry, the resource needs may differ between stages. This implies that there will always be a stage that has the lowest relative growth (or reproduction) rate, and growth (or reproduction) is resource limited (De Roos et al. 2008). Which stage is resource limited is an emergent property of the parameter settings. The key biological features of the stage-structured model are described below, and for a detailed mathematical description, we refer to De Roos et al. (2008).

To model the population, 3 stages and 2 resources are recognized (Fig. 1). The small juveniles (S) only forage on the resource in the shallow area $\left(R_{s}\right)$, and adults (A) only forage on the resource in the deeper area $\left(R_{d}\right)$. Large juveniles (L) may forage on both resources. Therefore, the fraction of time large juveniles spend in the shallow area or the deeper area $(\alpha)$ is varied.

We assume that both resources follow semi-chemostat dynamics, with growth rate $r$ and carrying capacity $K$. Using logistic growth will not quantitatively change the results (Guill 2009, Nilsson et al. 2010). The maximum equilibrium densities of the resource in the shallow habitat and the resource in the deeper habitat are scaled with fraction $\omega(0 \leq \omega \leq 1)$ so that:

$$
K_{\mathrm{s}}=(1-\omega) K_{\mathrm{m}}, \mathrm{K}_{\mathrm{d}}=\omega K_{\mathrm{m}}
$$

When $\omega<0.5$, the deep habitat is the more productive habitat, and when $\omega>0.5$, the shallow habitat is the more productive habitat (Fig. 2). For simplicity reasons, differences between resource levels at maximum capacity are scaled solely through $K$, following van de Wolfshaar et al. (2011). As differences in habitat productivity could have an effect on the population dynamics (van de Wolfshaar et al. 2011),

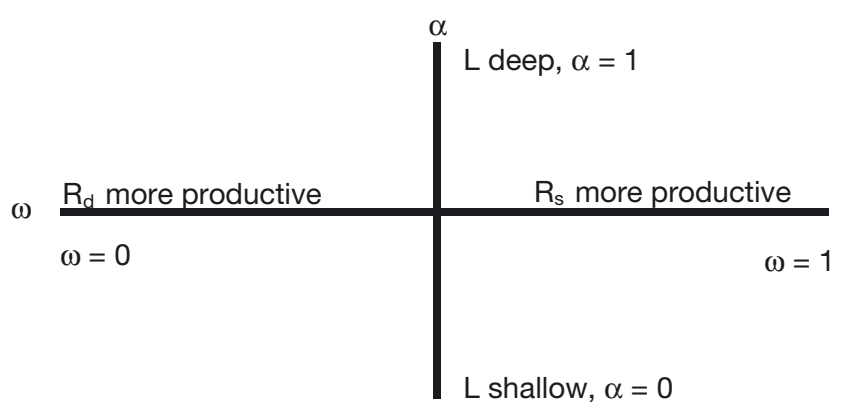

Fig. 2. When $\omega>0.5$, the shallow juvenile habitat is more productive than the deeper habitat; when $\omega<0.5$, the deeper habitat is more productive. When $\alpha$ is 1 , large juveniles forage only in the deeper habitat, and when $\alpha$ is 0 , they forage only in the shallow habitat

the effect of varying relative habitat productivity was included in the study.

All stages forage using a Holling Type II functional response with a half-saturation constant $\left(\mathrm{R}_{\mathrm{h}}\right)$ and a mass-specific maximum ingestion rate $\left(I_{\max }\right)$. The total ingested resource $\left(\mathrm{IR}_{i}\right)$ by a certain stage $i$ depends on the resource density according to:

$$
\mathrm{IR}_{i}=I_{\max , i}+0.1\left(\mathrm{R}_{(i)}\right)\left(\mathrm{R}_{\mathrm{h}}+\mathrm{R}_{(i)}\right)
$$

where $R_{(i)}$ can be $R_{s}$ in case of small juveniles and $R_{d}$ for adults. The total ingested resource intake of large juveniles depends on both resources and the fraction of time spent in the deeper habitat, $\alpha$ :

$\mathrm{IR}_{\mathrm{L}}=I_{\text {max, }}\left(\alpha \mathrm{R}_{\mathrm{s}}+(1-\alpha) \mathrm{R}_{\mathrm{d}}\right) /\left(\mathrm{R}_{\mathrm{h}}+\alpha \mathrm{R}_{\mathrm{s}}+(1-\alpha) \mathrm{R}_{\mathrm{d}}\right)$

When $\alpha=0$, the large juveniles spend all their time foraging on the resource in the shallow habitat, whereas when $\alpha=1$, they spend all their time foraging on the resource in the deeper habitat (Fig. 2).

The differential equations describing the dynamics of the resources in shallow and deeper habitat are then as follows:

$$
\begin{gathered}
\mathrm{dR}_{\mathrm{s}} / \mathrm{d} t=r\left(K_{\mathrm{s}}-\mathrm{R}_{\mathrm{s}}\right)-\left(\mathrm{S} \cdot \mathrm{IR}_{\mathrm{S}}+\mathrm{L} \cdot \mathrm{IR}_{\mathrm{Ls}}\right) \\
\mathrm{dR}_{\mathrm{d}} / \mathrm{d} t=r\left(K_{\mathrm{d}}-\mathrm{R}_{\mathrm{d}}\right)-\left(\mathrm{A} \cdot \mathrm{IR}_{\mathrm{A}}+\mathrm{L} \cdot \mathrm{IR}_{\mathrm{Ld}}\right)
\end{gathered}
$$

where $I_{\mathrm{Ls}}$ represents the resource consumption of large juveniles in the shallow habitat, and $\mathrm{IR}_{\mathrm{Ld}}$ represents the resource consumption of large juveniles in the deeper habitat.

The ingested resource is converted with an efficiency $\delta$, and minus the species mass-specific metabolic rate $T$, this gives the net biomass production for each stage $i$ :

$$
v_{i}(\mathrm{R})=\delta \mathrm{IR}_{i}-\mathrm{T}_{i}
$$


The following set of differential equations then describes the dynamics of the 3 stages of the population:

$$
\begin{aligned}
& \mathrm{dS} / \mathrm{d} t=v_{\mathrm{A}}^{+}\left(\mathrm{R}_{\mathrm{d}}\right) \mathrm{A}+v_{\mathrm{S}}\left(\mathrm{R}_{\mathrm{s}}\right) \mathrm{S}-\gamma\left(v_{\mathrm{S}}^{+}\left(\mathrm{R}_{\mathrm{s}}\right)\right) \mathrm{S}-\mu_{\mathrm{s}} \mathrm{S} \\
& \mathrm{dL} / \mathrm{d} t=\gamma\left(v_{\mathrm{S}}^{+}\left(\mathrm{R}_{\mathrm{s}}\right)\right) \mathrm{S}+v_{\mathrm{L}}\left(\mathrm{R}_{\mathrm{s}, \mathrm{d}}\right) L-\gamma\left(v_{\mathrm{L}}^{+}\left(\mathrm{R}_{\mathrm{s}, \mathrm{d}}\right)\right) \mathrm{L}-\mu_{\mathrm{L}} \mathrm{L} \\
& \mathrm{dA} / \mathrm{d} t=\gamma\left(v_{\mathrm{L}}^{+}\left(\mathrm{R}_{\mathrm{s}, \mathrm{d}}\right)\right) \mathrm{L}+v_{\mathrm{A}}\left(\mathrm{R}_{\mathrm{d}}\right) \mathrm{A}-\left(v_{\mathrm{A}}^{+}\left(\mathrm{R}_{\mathrm{d}}\right)\right) \mathrm{A}-\mu_{\mathrm{A}} \mathrm{A}
\end{aligned}
$$

where $\mu_{i}$ is the total mortality rate in stage $i, \gamma\left(v_{i}^{+}(\mathrm{R})\right)$ is the rate at which small juveniles and large juveniles mature to the next stage, and $v_{A}^{+}(R)$ is the reproduction rate of adults.

The maturation rate depends on the biomass individuals have to accumulate within the stage, the net biomass production of the stage, and mortality:

$$
\gamma\left(v_{i}^{+}(\mathrm{R})\right)=v_{i}(\mathrm{R})-\mu_{i} /\left(1-z^{\left(1-\mu_{i} / v_{i}\left(\mathrm{R}_{i}\right)\right)}\right)
$$

with $z$ being the ratio between the mass at which an individual enters the stage and the mass at which an individual develops to the next stage. For adults, it is assumed that all surplus energy is converted into offspring. The net biomass production of adults then equals the reproduction rate. To ensure that negative maturation or reproduction does not occur, biomass is only transferred between stages when the net energy intake is positive $\left(v_{i}(\mathrm{R})>0\right)$. If the net biomass production is negative, starvation occurs, and maturation and reproduction do not take place, i.e. $v_{\mathrm{A}}^{+}(\mathrm{R})=0, \gamma\left(v_{i}^{+}(\mathrm{R})\right)=0$.

\section{Parameters}

Parameter values for maintenance and ingestion used for the general case were published by van de Wolfshaar et al. (2011). These are based on massspecific rates proportional to the quarter power of adult body sizes (Yodzis \& Innes 1992), and the constants of the power laws are based on ectothermic species (De Roos et al. 2008). van de Wolfshaar et al. (2011) performed a sensitivity analysis on a similar model as used here with 2 resources and 2 stages and confirmed that variation in the other parameter values did not qualitatively change the results regarding general patterns. In contrast to the model used by van de Wolfshaar et al. (2011), 3 stages are used instead of 2 . As a result, 1 additional stage boundary is needed. The ratio between size at birth and size at maturation (parameter $z$ ) used by van de Wolfshaar et al. (2011) of $1 \times 10^{-5}$, an order of magnitude of growth common for fish species, was therefore divided for the 2 juveniles stages used here, $1 \times 10^{-3}$ and $1 \times 10^{-2}$. An increase in background mortality

\begin{tabular}{|c|c|c|c|}
\hline Variable & Value & Unit & Description \\
\hline$S$ & & $\operatorname{g~l}^{-1}$ & Juvenile biomass \\
\hline$L$ & & $\mathrm{~g} \mathrm{l}^{-1}$ & Large juvenile biomass \\
\hline$A$ & & $g \mathrm{l}^{-1}$ & Adult biomass \\
\hline$R$ & & $\mathrm{~g} \mathrm{l}^{-1}$ & Resource biomass \\
\hline$I_{\max }$ & 13 & $\operatorname{g~g}^{-1} d^{-1}$ & Maximum intake rate \\
\hline$T$ & 1 & $\operatorname{g~g}^{-1} \mathrm{~d}^{-1}$ & Maintenance rate \\
\hline$Z_{J-L J}$ & 0.001 & & $\begin{array}{l}\text { Size ratio small juvenile } \\
\text { to large juvenile }\end{array}$ \\
\hline$Z_{L J-A}$ & 0.01 & & $\begin{array}{l}\text { Size ratio large juvenile } \\
\text { to adult }\end{array}$ \\
\hline$\Delta$ & 0.36 & & Food conversion factor \\
\hline$\mu$ & 0.05 & $d^{-1}$ & Background mortality \\
\hline $\mathrm{R}_{\mathrm{h}}$ & 0.1 & $\mathrm{~g} \mathrm{l}^{-1}$ & $\begin{array}{l}\text { Feeding half saturation } \\
\text { constant }\end{array}$ \\
\hline$r$ & 1 & $d^{-1}$ & Resource regrowth rate \\
\hline$K_{\mathrm{m}}$ & 10 & $g \mathrm{l}^{-1}$ & Maximum carrying capacity \\
\hline$\omega$ & Varied & & Carrying capacity scalar \\
\hline$\alpha$ & Varied & & $\begin{array}{l}\text { Partitioning large juveniles } \\
\text { shallow-deep habitat }\end{array}$ \\
\hline E & Varied & $d^{-1}$ & Fishing intensity \\
\hline$C_{A}$ & 1 & & Catchability adult stage \\
\hline$C_{L}$ & 1 & & $\begin{array}{l}\text { Catchability large juvenile } \\
\text { stage in deep habitat }\end{array}$ \\
\hline
\end{tabular}

Table 1. Model variables, parameters and their values for the generalized parameterization (taken from van de Wolfshaar et al. 2011)

decreases the scope for alternative stable states (results not shown), and juvenile mortality decreases population persistence more than adult mortality does (Nilsson et al. 2010, van de Wolfshaar et al. 2011).

Mortality of all stages is set to $0.05 \mathrm{~d}^{-1}$. In addition, adults and large juveniles in the deep habitat may be subjected to fishing mortality, where the realized mortality is a product of fishing intensity and stagespecific catchability. The fishing intensity as used here is a model assumption and does not relate to fishing mortality observed in reality. The use of a single parameter, called fishing intensity, allows simultaneous scaling of additional mortality for adults and large juveniles in the deeper habitat. All parameter values used are listed in Table 1.

\section{RESULTS}

\section{Changing relative habitat productivity}

The model results display the changes of equilibrium biomass of the different stages as a function of changes in a parameter value. Here, a model with 2 habitats and hence 2 resources is used. The relative difference between the productivity of the 2 habitats 

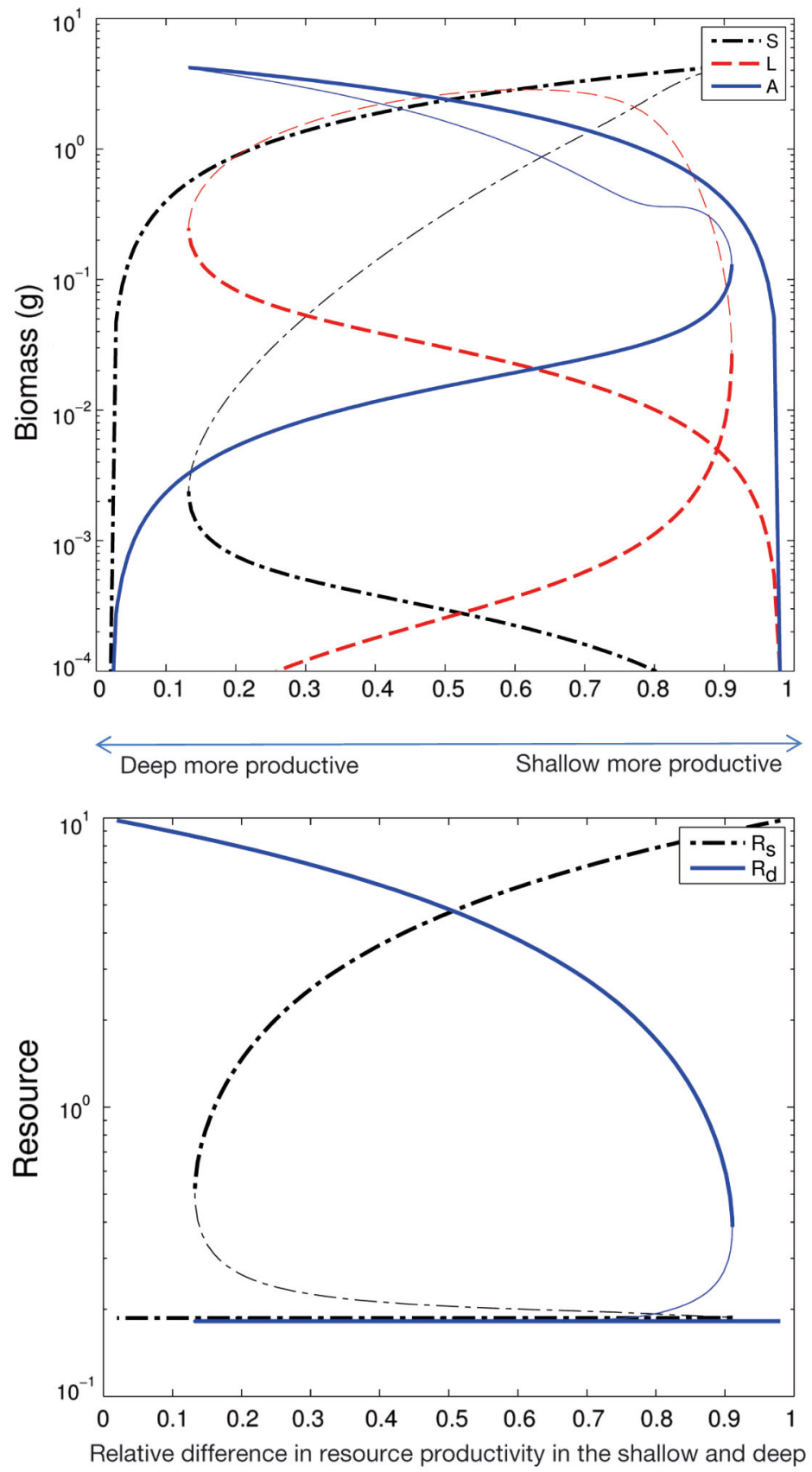

Fig. 3. Biomass of the 3 stages, small juveniles (S), large juveniles (L) and adults (A) (top) and resource densities in the shallow habitat $\left(\mathrm{R}_{\mathrm{s}}\right)$ and in the deep habitat $\left(\mathrm{R}_{\mathrm{d} i}\right.$ bottom) as a function of the relative difference in resource productivity in the shallow and deep habitat $(\omega)$. Stable states are shown in thick lines, unstable states in thin lines. The fraction of time large juveniles spend in the deeper area: $\alpha=0.3$

is varied. Large differences in productivity between the deeper (adult) and shallow (juvenile) habitats limit population persistence, as differences that are too large imply that one habitat is not productive enough to support growth or maturation of the stage present and hence to support the population as a whole (Fig. 3). When the deep habitat is more productive and the shallow habitat is least productive $(\omega$ close to zero), most biomass is in the small juvenile stage. The small juveniles are resource limited $(\omega$ close to zero) and have little resource for growth and maturation to the next stage. The least biomass is in the large juvenile stage since the influx of small juveniles is hampered by low resource availability and because the large individuals spend time in the deep habitat where they can grow and mature quickly, because the deep habitat is most productive. With increasing $\omega$, total population biomass increases because the productivity of both habitats becomes more equal. When $\omega$ reaches 0.9 , the stable state collapses to an alternative stable state with most biomass in the adult stage and least biomass in the small juvenile stage. In this state, the adult stage is most resource limited and reproduction is hampered, especially when the deep habitat is the least productive $(\omega>0.5)$. With a decline in $\omega$ again, this state returns to the original state if $\omega<0.13$. The resource follows a similar pattern with low resource density in the shallow habitat and high resource density in the deep habitat in the state with high biomass of the small juveniles (Fig. 3). This means that the individuals in the shallow habitat are resource limited, despite values of $\omega$ close to 1 . The opposite is the case for the alternative equilibrium with high adult biomass; then, the resource density is low in the deep habitat and high in the shallow habitat. These results indicate that there is scope for alternative stable states when varying the relative habitat productivity (corroborating the results presented for a 2 stage model by van de Wolfshaar et al. 2011). The range of values of $\omega$ for which the population can persist is dependent on the total productivity (carrying capacity) of the system and is independent of the time large juveniles spend in the deep habitat (result not shown, but see also van de Wolfshaar et al. 2011).

\section{Changing large juvenile habitat use}

When allowing the large juveniles, the intermediate stage, to use the deep habitat more (an increase of $\alpha$ ) for a given relative productivity, the biomass of the large juvenile stage decreases while the biomass of the small juveniles remains constant (Fig. 4). Adult biomass shows an initial increase with increasing $\alpha$ but remains constant thereafter. The large juveniles are entering the deep habitat, the habitat with the highest resource density, with rapid growth and mat- 
Small juvenile dominated equilibrium
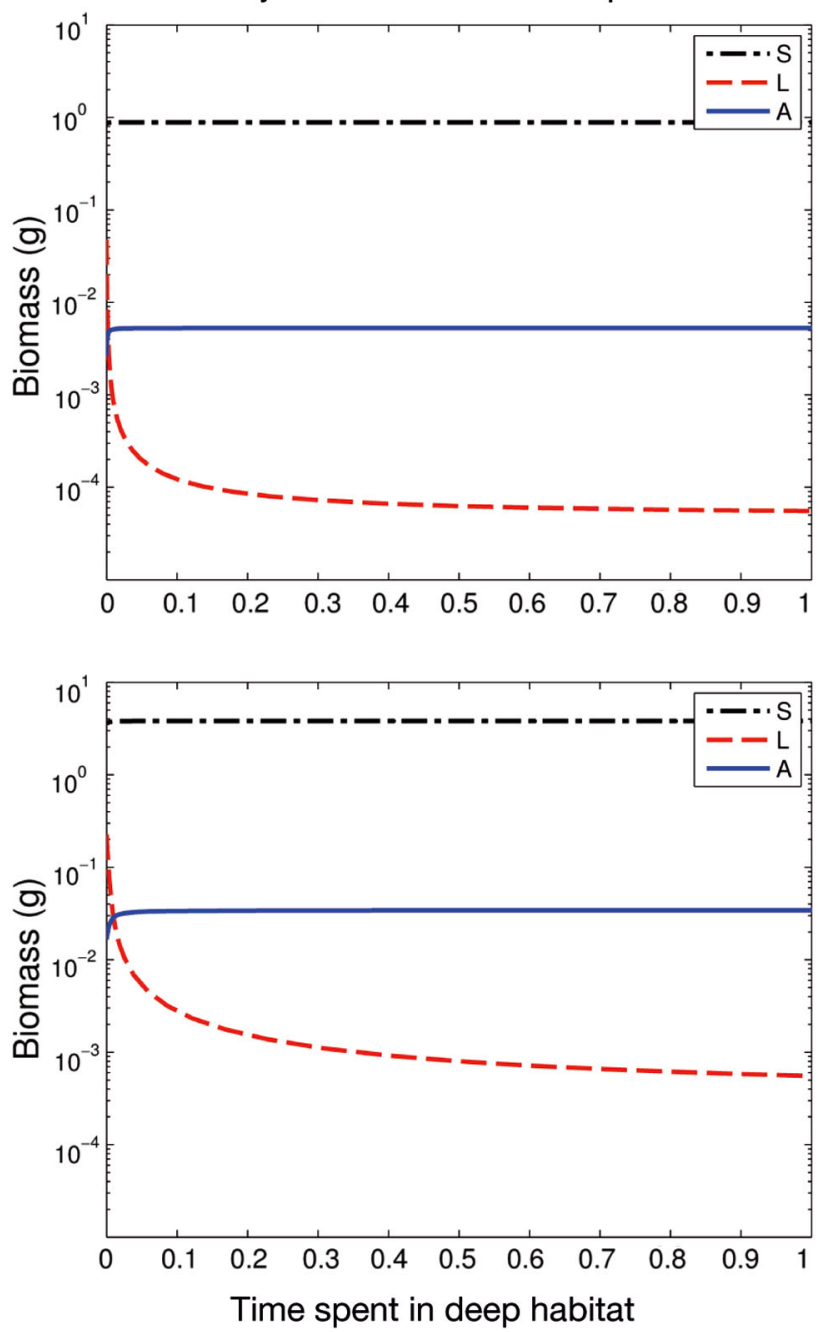

Adult dominated equilibrium

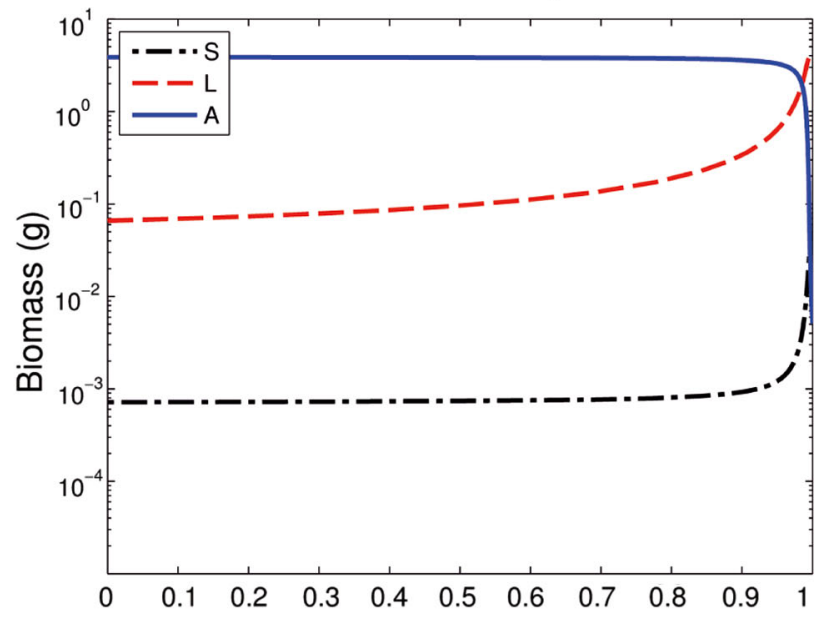

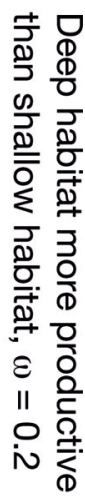

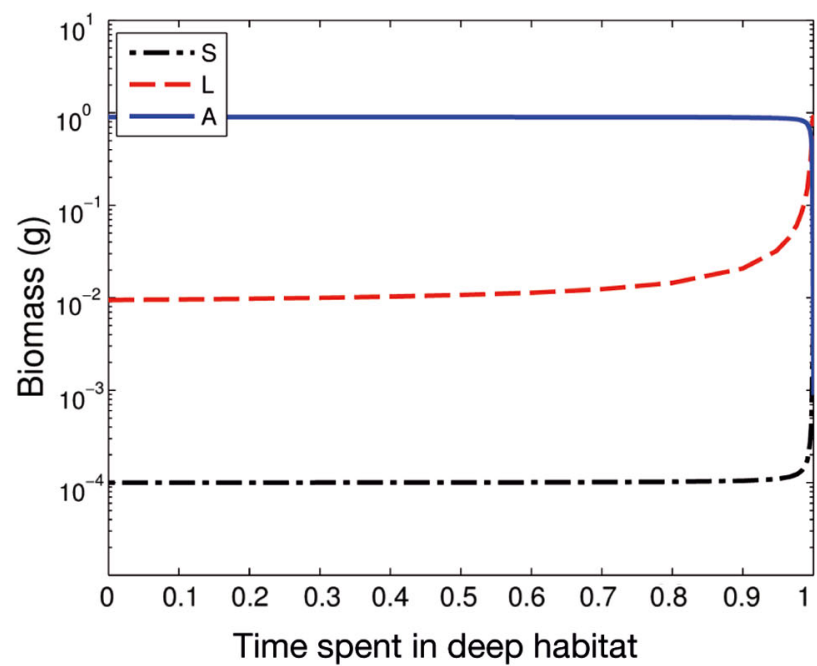

Fig. 4. Change in stage biomass (S: small juveniles; L: large juveniles; A: adults) as function of the time large juveniles spent in the deep habitat $(\alpha)$ for different values of the relative difference in resource productivity in the shallow and deep habitat $(\omega)$, and for the 2 different stable states
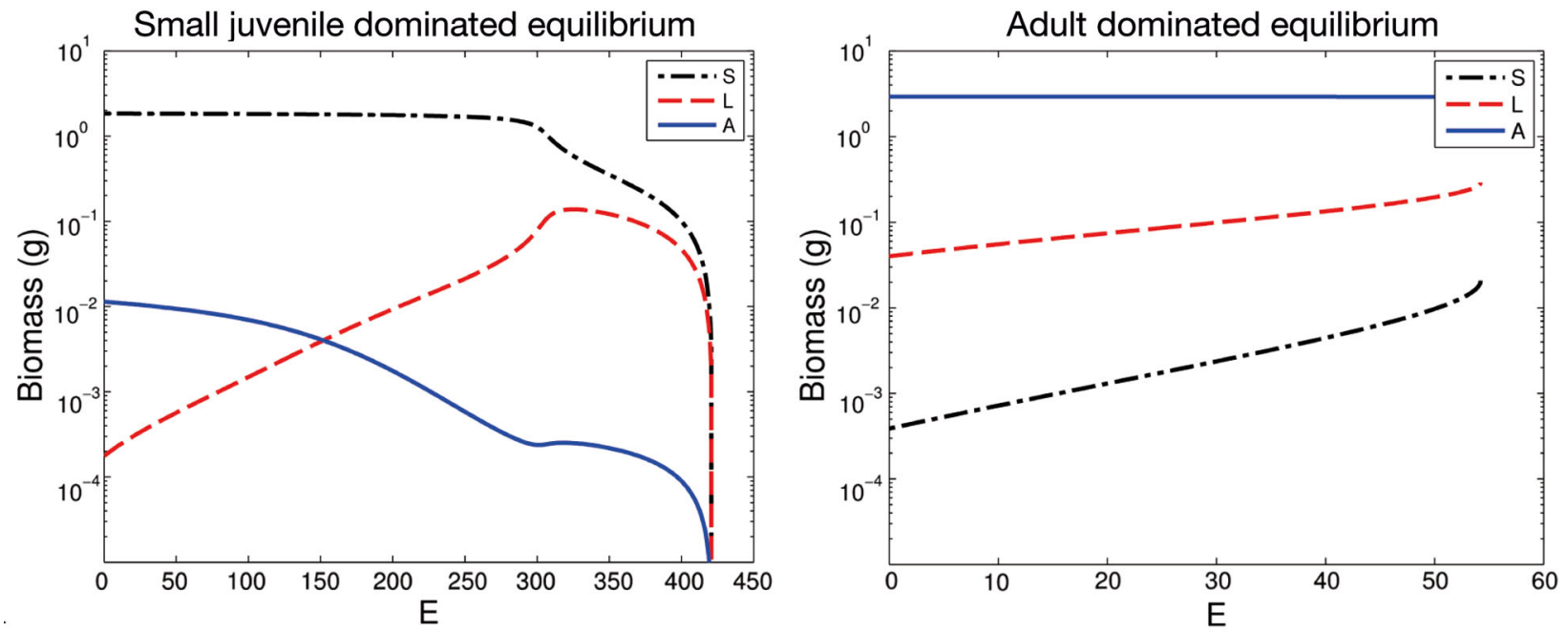

Fig. 5. Change in stage biomass (S: small juveniles; L: large juveniles; A: adults) as function of fishing intensity $E$ for the 2 different stable states $(\omega=0.4$ and $\alpha=0.3)$ 
uration to the adult stage. The adults are reproducing at maximum capacity, and the low resource density in the shallow habitat limits maturation of the small juveniles. This is the case irrespective of the value of $\omega$, the relative habitat productivity. A change in relative habitat productivity increases the total biomass in the system but not the qualitative patterns in biomass. However, when in the alternative stable state, dominated by adult biomass, an increase in $\alpha$ results in an increase in large juvenile biomass. For values of $\alpha$ close to 1 , small juvenile biomass increases and adult biomass decreases. The biomass of large juveniles increases because they are spending more time in the deep habitat, which has low resource densities. Here, resource competition hampers growth and maturation, and biomass builds up. Again, the pattern is stable for different values of relative habitat productivity $(\omega)$.

\section{Changing fishing intensity}

When introducing fishing mortality for adults and large juveniles in the deep habitat, the dynamics respond differently between the 2 alternative stable states (Fig. 5). When the population is in the state with most biomass in the small juvenile stage, the population can endure high values of fishing intensity before collapse. With increasing fishing intensity, adult biomass decreases while large juvenile biomass increases. The increase in large juvenile biomass is an indirect result from the fishing mortality. The decrease in adult biomass results in a decrease in reproduction. The decrease in reproduction reduces the competition in the small juvenile stage, which in turn allows for an increase in maturation to the large adult stage. At a fishing intensity around 300, the reduction in adult biomass is such that it leads to a profound reduction in small juvenile biomass after which they are no longer resource limited and mature at maximum rate. The large juvenile biomass is then at its peak because now juveniles become resource limited, which delays maturation to the adult stage. With an even further increase in fishing intensity, the biomass removal from the system can no longer be compensated, and the biomass of all stages decreases.

When the population is in the adult biomass dominated state, the increase of fishing intensity leads to an increase of juvenile biomass in both stages, while adult biomass is hardly affected (Fig. 5, right panel). The adult biomass removal by fishing is compensated through increased reproduction. Both juvenile stages mature at maximum rate, except for those large juveniles that are in the deep habitat. They suffer from the low resource availability and fishing mortality. With even higher fishing intensity, the population becomes extinct.

\section{DISCUSSION}

Changes in ontogenetic habitat shifts may cause changes in intraspecific competition affecting population dynamics. This study, based on a life-stage structured population model, demonstrated that differences in productivity of the shallow and deep habitat influence the population response to a stagespecific change in habitat use in a quantitative manner. The model is especially applicable for species, such as flatfish, with a strong dependence on coastal areas as nursery grounds (Able \& Fodrie 2015), but may also apply to other species (Seitz et al. 2014). For a given productivity, adult biomass increases with increasing time large juveniles spend in the deep habitat. The results described here illustrate general concepts concerning habitat productivity and habitat use. Changes in habitat use by life stages can influence population dynamics, which may have implications for the way fisheries and habitats should be managed.

Two alternative stable states exist: one dominated by small juvenile biomass and one by adult biomass. Alternative stable states may arise in models of species with complex life cycles and differences in habitat productivity between adult and juvenile resources (van de Wolfshaar et al. 2011). Assumptions on resource dynamics do not affect the occurrence of alternative stable states (Guill 2009). Increased (fishing) mortality reduces the scope for alternative stable states (corroborating van de Wolfshaar et al. 2011). The state dominated by adult biomass collapses at lower fishing intensity than the state dominated by small juvenile biomass. This collapse occurs after only a minor change in adult biomass, while juvenile biomass showed a large increase. This illustrates that stock indicators need to consider the whole population and should not be limited to the adult stage.

When including fishing mortality in the deeper habitat, the effects of increased competition between adults and large juveniles, resulting from the habitat shift of larger juveniles, are reduced by the removal of biomass through harvest. As a result of fishing mortality and the subsequent changes in resource competition, overcompensation of large juvenile biomass occurs (De Roos et al. 2007, van de Wolfshaar et al. 2011). Increasing juvenile mortality will affect the 
population dynamics depending on the state the population is in (De Roos et al. 2007, van de Wolfshaar et al. 2011). When resource competition is most severe among juveniles, increased juvenile mortality reduces the competition in the shallow habitat and hence will promote maturation to the next stage and promote biomass in the forthcoming stages. When resource competition is most severe among adults, increased juvenile mortality will have little effect on the population dynamics but will reduce the total biomass. Increased juvenile mortality will reduce the scope for alternative stable states and will more negatively affect population persistence than corresponding levels of adult mortality (Nilsson et al. 2010, van de Wolfshaar et al. 2011).

Understanding the mechanism driving changes in habitat use may guide management to anticipate these changes. Recent studies on North Sea plaice, a boreal flatfish species common in the North Sea, showed an increase in mean depth of $\sim 3.6 \mathrm{~m}$ per decade (Dulvy et al. 2008) as well as a change in the mean geographical distribution (Engelhard et al. 2011). North Sea plaice age 1+ currently no longer occur in the shallow coastal zone, and findings in recent literature show more juveniles, especially large juveniles, present in deeper waters (van Keeken et al. 2007, Beare et al. 2010, Teal et al. 2012, van Hal et al. in press), while the North Sea stock and spawning biomass has increased over the past 10 yr (ICES 2014). The absence of large plaice juveniles in coastal nurseries has been attributed to temperature (van Keeken et al. 2007, van der Veer et al. 2011, Teal et al. 2012, van Hal et al. in press). It was suggested that higher temperatures increase energy demands in juvenile plaice, and the resulting reduction in the scope for growth causes an earlier offshore movement (Teal et al. 2012). van Hal et al. (in press) compared the change in depth distribution of several flatfish species and found that only the distribution of the boreal species has shifted towards deeper parts thereby maintaining a constant temperature, while the distribution of Lusitanian species did not change. Although we acknowledge that temperature affects physiological rates, it was not considered in the model presented here.

An important issue implied by large juveniles switching habitats is the management of marine protected areas. These areas are typically established at fixed locations, but a change of habitat use by the protected species or life-stage might call for relocation of the protected area. With the intense use and planning of marine areas by humans, with fishing, shipping, pipelines, etc., relocation of protected areas may be hard to accomplish. The 'plaice box' in the German Bight of the North Sea may serve as an illustrative example. After establishment of the protected area, called the 'plaice box', the size classes of plaice that were supposed to profit from the measure moved out of the area, most likely due to increasing sea water temperatures that occurred almost simultaneously with the area closure (Beare et al. 2010). Shifts in habitat have potential consequences for habitat protection programs or no-take zones when the target individuals move out of the protected area. Furthermore, shifts in habitat use may have consequences for harvesting and bycatch. By-catches of plaice with sizes below the legal landing size have increased from 18 to $30 \%$ during 1970 to 1990, and up to $50 \%$ in 2003 (van Keeken et al. 2007). Large juveniles moving into potentially fished areas result in higher bycatch mortality from the fisheries. However, the adults in the deeper habitat are also affected by juvenile migration. Increased crowding in deeper areas has already been observed (Van Keeken et al. 2004) and would potentially increase with increasing offshore migration. In conclusion, from a management perspective, a shift of juveniles towards deeper habitats needs to be addressed, and an understanding of the mechanisms causing and following these changes will aid in designing marine protected areas, resolving bycatch issues and understanding changes in adult growth and reproduction. Safeguarding nursery functions in a changing environment requires monitoring of the juvenile life stages in a range of habitats, a better understanding of how changes in nursery habitat quality and quantity translate into changes in growth and mortality, and an adaptive management strategy.

Acknowledgements. This research is part of the ICES Working Group on the Value of coastal Habitat of Exploited Species (WGVHES), and the authors thank the other group members for discussion. K.W. and I.T. were supported by IMARES. J.G.S. was funded through the project 'Kystfisk' by the EU and the Ministry of Food, Agriculture and Fisheries through the European Fisheries Fund: 'Denmark and the EU invest in sustainable fisheries and aquaculture'. H.W. was supported by the Swedish Agency for Marine and Water Management. We thank the editor and 2 anonymous reviewers for their valuable comments that helped us improve the manuscript.

\section{LITERATURE CITED}

Able KW, Fodrie FJ (2015) Distribution and dynamics of habitat use by juvenile and adult flatfishes. In: Gibson RN, Nash RDM, Geffen AJ, van der Veer HW (eds) Flatfishes: biology and exploitation. John Wiley \& Sons, Chichester, p 242-282 
Beare DJ, Burns F, Greig A, Jones EG and others (2004) Long-term increases in prevalence of North Sea Fishes having southern biogeographic affinities. Mar Ecol Prog Ser 284:269-278

Beare D, Rijnsdorp AD, van Kooten T, Fock H and others (2010) Study for the revision of the plaice box - final report. IMARES report C002/10, IJmuiden

> De Roos AM, Schellekens T, van Kooten T, van de Wolfshaar KE, Claessen D, Persson L (2007) Food-dependent growth leads to overcompensation in stage-specific biomass when mortality increases: the influence of maturation versus reproduction regulation. Am Nat 170: E59-E76

> De Roos AM, Schellekens T, van Kooten T, van de Wolfshaar KE, Claessen D, Persson L (2008) Simplifying a physiologically structured population model to a stagestructured biomass model. Theor Popul Biol 73:47-62

Dulvy NK, Rogers SI, Jennings S, Stelzenmüller V, Dye SR, Skjoldal HR (2008) Climate change and deepening of the North Sea fish assemblage: a biotic indicator of warming seas. J Appl Ecol 45:1029-1039

Edwards M, Beaugrand G, Reid PC, Rowden AA, Jones MB (2002) Ocean climate anomalies and the ecology of the North Sea. Mar Ecol Prog Ser 239:1-10

Engelhard GH, Pinnegar JK, Kell LT, Rijnsdorp AD (2011) Nine decades of North Sea sole and plaice distribution. ICES J Mar Sci 68:1090-1104

Gibson RN (1994) Impact of habitat quality and quantity on the recruitment of juvenile flatfishes. Neth J Sea Res 32: 191-206

Guill C (2009) Alternative dynamical states in stagestructured consumer populations. Theor Popul Biol 76: 168-178

Harley CDG, Hughes AR, Hultgren KM, Miner BG and others (2006) The impacts of climate change in coastal marine systems. Ecol Lett 9:228-241

Hopkins TS, Bailly D, Støttrup JG (2011) A systems approach framework for coastal zones. Ecol Soc 16(4):25

ICES (International Council for the Exploration of the Sea) (2014) Report of the Working Group for the Assessment of Demersal Stocks in the North Sea and Skagerrak (WGNSSK), 30 April-7 May 2014. ICES CM 2014/ ACOM:13

McClanahan T, Allison EH, Cinner JE (2015) Managing fisheries for human and food security. Fish Fish 16: 78-103

Nilsson KA, Persson L, Van Kooten T (2010) Complete compensation in Daphnia fecundity and state-specific biomass in response to size-independent mortality.

Editorial responsibility: Jake Rice,

Ottawa, Ontario, Canada
J Anim Ecol 79:871-878

Petitgas P, Rijnsdorp AD, Dickey-Collas M, Engelhard GH and others (2013) Impacts of climate change on the complex life cycles of fish. Fish Oceanogr 22:121-139

Rijnsdorp AD, Peck MA, Engelhard GH, Möllmann C, Pinnegar JK (2009) Resolving the effect of climate change on fish populations. ICES J Mar Sci 66:1570-1583

Rindorf A, Lewy P (2006) Warm, windy winters drive cod north and homing of spawners keeps them there. J Appl Ecol 43:445-453

Schröder A, Persson L, De Roos AM (2005) Direct experimental evidence for alternative stable states: a review. Oikos 110:3-19

Seitz RD, Wennhage H, Bergström U, Lipcius RN, Ysebaert $\mathrm{T}$ (2014) Ecological value of coastal habitats for commercially and ecologically important species. ICES J Mar Sci 71:648-665

> Teal LR, van Hal R, van Kooten T, Ruardij P, Rijnsdorp AD (2012) Bio-energetics underpins the spatial response of North Sea plaice (Pleuronectes platessa L.) and sole (Solea solea L.) to climate change. Glob Change Biol 18: 3291-3305

> van de Wolfshaar KE, HilleRisLambers R, Gårdmark A (2011) Effect of habitat productivity and exploitation on populations with complex life cycles. Mar Ecol Prog Ser 438:175-184

> van de Wolfshaar KE, Schellekens T, Poos JJ, van Kooten T (2012) Interspecific resource competition effects on fisheries revenue. PLoS ONE 7:e53352

> van der Veer HW, Koot J, Aarts G, Dekker R, Diderich W, Freitas V, Witte JIJ (2011) Long-term trends in juvenile flatfish indicate a dramatic reduction in nursery function of the Balgzand intertidal, Dutch Wadden Sea. Mar Ecol Prog Ser 434:143-154

van Hal R, van Kooten T, Rijnsdorp AD (in press) Temperature induced changes in size dependent distributions of two boreal and three Lusitanian flatfish species: a comparative study. J Sea Res, doi:10.1016/j.seares.2015.06. 020

van Keeken OA, van Hoppe M, Grift RE, Rijnsdorp AD (2007) Changes in the spatial distribution of North Sea plaice (Pleuronectes platessa) and implications for fisheries management. J Sea Res 57:187-197

Vasconcelos RP, Le Pape O, Costa MJ, Cabral HN (2013) Predicting estuarine use patterns of juvenile fish with Generalized Linear Models. Estuar Coast Shelf Sci 120: 64-74

- Yodzis P, Innes S (1992) Body size and consumer-resource dynamics. Am Nat 139:1151-1175

Submitted: July 15, 2014; Accepted: October 19, 2015

Proofs received from author(s): November 20, 2015 